\title{
A Multi-Program Approach to Student Retention and Success
}

\section{Dr. Paige E. Smith, University of Maryland, College Park}

Paige Smith, Ph.D. is the director of the Women in Engineering Program in the A. James Clark School of Engineering at the University of Maryland. Paige has over 20 years of experience with recruiting and retaining diverse populations in engineering. Under her leadership, the Women in Engineering Program received the 2016 Women in Engineering Initiative Award from WEPAN and the 2008 National Engineers Week Introduce a Girl to Engineering Day Award. She is the principal investigator for a National Science Foundation's Science, Technology, Engineering, and Mathematics Talent Expansion Program (STEP) grant called the Successful Engineering Education and Development Support (SEEDS) Program. SEEDS extends successful women in engineering retention programs to all first-year and new external transfer students in the Clark School. Paige is a Past President of the Women in Engineering ProActive Network (WEPAN). Paige earned her Ph.D. and M.S. in industrial and systems engineering and B.S. in engineering science and mechanics from Virginia Tech.

\section{Ms. Elizabeth R. Kurban, University of Maryland, College Park}

Elizabeth Kurban serves as the Assistant Director of Retention for the Women in Engineering Program at the University of Maryland Clark School of Engineering. Elizabeth's professional and research interests broadly surround STEM-field access and persistence for women and underrepresented minoritized student populations. She is passionate about equity, diversity, and inclusion in higher education, particularly in the context of engineering. Elizabeth is also a Ph.D. Candidate in Higher Education at the University of Maryland's College of Education. Prior to her journey at UMD, Elizabeth worked in higher education policy research in Washington, DC and earned an M.S.Ed in Higher Education Administration from the University of Pennsylvania and an M.A. in Cognitive Science from the University of Delaware.

\section{Dr. Catherine T. Amelink, Virginia Tech}

Dr. Amelink is Director of Graduate Programs and Assessment in the College of Engineering, Virginia Tech. She is also an affiliate faculty member in the Departments of Engineering Education and Educational Leadership and Policy Studies at Virginia Tech. 


\title{
A Multi-Program Approach to Student Retention and Success
}

\begin{abstract}
Programs that address the needs of first year engineering students have traditionally been designed to create community and facilitate inclusion. Students are more likely to be retained into their second year when guided by structures of engagement and support through purposefully-designed programs (Soldner, Rowan-Keyon, Inkelas, Garvey, \& Robbins, 2012, National Academies, 2014; Seymour \& Hewitt, 1997). These programs can include living learning communities (Soldner et al., 2012), mentoring experiences (Baier, Markman, \& PerniceDuca, 2016), and summer bridge interventions (Lee, Seimetz, \& Amelink, 2014; Yoder, 2012). While research has underscored how these programs can encourage retention, much less is understood about how programs can work together to address the needs of at-risk student populations, particularly for those in science, technology, engineering and mathematics (STEM) programs. This paper will describe the first-year intervention programs designed for underrepresented students in engineering (i.e., African Americans, Native Americans, Hispanics, and females of all races) at the University of Maryland, including a summer bridge program, mentoring program, and engineering specific living learning communities. Important implications about program design drawn from the longitudinal evaluation of these retention programs will be discussed.
\end{abstract}

\section{The Successful Engineering Education and Development Support Program}

The Successful Engineering Education and Development Support (SEEDS) Program is comprised of several multifaceted retention programs within the A. James Clark School of Engineering at the University of Maryland. Funded through a grant from the National Science Foundation (DUE \#0969232), the SEEDS program was piloted in 2010 and fully implemented in 2011. The goals of the SEEDS program include "(1) facilitating the first year students' and new transfer students' transition into the school of engineering; (2) increasing students' commitment to engineering majors through career clarification and goal setting; (3) reducing the barriers to success that students may face, particularly those for women and underrepresented students; and (4) enhancing the positive personal and environmental factors for students in engineering." (Smith, Fourney, \& Pertmer, 2009) Ultimately, the SEEDS program seeks to promote persistence and success among engineering students, particularly through their first year in the Clark School of Engineering.

The SEEDS program is comprised of a series of programs, including the Engineering Living \& Learning Communities of Flexus (women) and Virtus (men), the Peer Mentoring Program, and the First Year Summer Experience (FYSE).

\section{Engineering Living \& Learning Communities}

The Flexus Program. Flexus is a cohort-based living and learning community (LLC) designed specifically for female engineering students (refer to Samuelson, Litzler, Staples, \& Smith, 2014 for a comprehensive overview of Flexus). The Flexus program was developed initially through a generous grant from a former Associate Dean of the Clark School, gifted to the University of Maryland's Women in Engineering Program. In addition to promoting gender diversity in the 
field of engineering, the primary goal of Flexus is to cultivate community among first-year and second-year female engineering students (Tinto, 2003). Living and learning communities, such as Flexus, not only increase support through peer interactions, but increase students' likelihood of being retained through their second year (Seymour \& Hewitt, 1994; Soldner, Rowan-Kenyon, Inkelas, Garvey, \& Robbins, 2012; Samuelson et al., 2014).

The living and learning programs extend over students' first- and second-year in the Clark School. Students are recruited to become a part of the program throughout the spring recruitment season. Upon enrollment in the Flexus program, students are housed together in the same residence hall and registered for a one-credit seminar course, which continues each semester for the first two years. The first year Flexus seminars are specifically geared toward facilitating success during the college experience through core engineering courses and in future careers in engineering. The curriculum is structured for technical, professional, and personal development. While the majority of the seminar classes are held exclusively for Flexus, there are several cocurricular classes that are combined with the male LLC, Virtus. This allows for a broader community to be built among men and women across the male and female LLCs.

The first year Flexus seminar focuses on adjustment into engineering and the university, addressing skills necessary to succeed in college, such as time management, study skills, critical thinking, and awareness of various resources for students on campus. In addition, the class emphasizes the importance of teamwork through engaging in several group activities. The first year course also provides dedicated time in class to address challenges in the first two engineering courses students take, and provides an opportunity for students to work in groups to solve practice problems in challenging content areas of these courses. Furthermore, the Flexus program offers regular tutoring hours for its students within their shared residence hall. In the latter half of the year, the emphasis changes to professional and career development, such as interviewing skills, and how to research companies. The second-year Flexus course is geared more toward personal, professional, and leadership development, and preparation for careers in the field of engineering (Seymour et al., 1994). One aspect of the course focuses on the experiences of women in the field, addressing experiences of sexism and gender discrimination, and the ways in which to promote gender equality in STEM fields. Throughout the second year, Flexus students develop an awareness of self through completing instruments such as the StrengthsQuest for leadership development, beginning to explore information about potential career opportunities and professional development experiences. Other topics include ethics and diversity within the context of engineering leadership development. The program incorporates local engineering-related field trips and visits from speakers, including research presentations from faculty members and/or local women engineers. Each semester, the program staff members offer mid-semester advising to members of the living and learning communities.

Outside of the classroom, students participate in various extracurricular, social, and volunteer activities with a focus on community service and engineering outreach. These include mentoring and leadership opportunities designed to contribute to their leadership development and selfefficacy (Seymour et al., 1994). Part of the Flexus membership requirement includes engaging in activities with students outside of the classroom. At the beginning of the semester, LLC staff provides suggestions for activities, speakers, volunteer opportunities, and events on campus, in which students are encouraged to participate. The program staff also encourages Flexus first-year and second-year students to attend events with one another. This facilitates cross-cohort 
relationship development and provides first-year students with exposure to the experiences of second-year students, while also allowing second-year students to take on mentorship roles (Tinto, 2003). Another important aspect of Flexus is the opportunity it provides for leadership development. Students within the program elect an executive board (including a President, Vice President, and a few committee leaders) who plan and implement various social activities throughout the semester. The shared residence hall and student lounge are common gathering spaces for Flexus events, which makes attending the events together easy and convenient. These events, which range from field trips to Washington, DC to ice cream socials, have the goal of promoting community and friendship among the students (Seymour et al., 1994; Soldner et al., 2012).

The Virtus Program. Following the implementation of Flexus, Virtus was added to the SEEDS portfolio. Virtus was developed to provide a living and learning community for male engineering students. Aligned with many of the goals of Flexus, the primary focus of Virtus is on promoting community and support among first- and second-year engineering students. Through academic, social, and professional support services, Virtus seeks to better retain male students, while facilitating success through graduation (Soldner et al., 2012; Tinto, 2003). In many ways, Virtus is aligned with the curriculum and structure of Flexus. For example first-year students are required to live in a common residence hall, participate in a one credit seminar each semester, and participate in various academic, social and professional development activities.

Through various types of activities, programs, and services as living and learning communities, Flexus and Virtus facilitate both academic and social integration within the Clark School. All of living and learning students are required to participate in the peer mentoring program.

\section{SEEDS Peer Mentoring}

The SEEDS Peer Mentoring program was designed to be inclusive of all first-year engineering students and new transfer students in the Clark School. The primary goal of the program is to facilitate mentoring relationships among new engineering students with upper-level students. Previous research suggests that mentoring relationships among engineering students can encourage positive academic and social integration (Baier, Markman, \& Pernice-Duva, 2016; Wallace \& Haines, 2004).

Each year about 50-60 peer mentors are hired and trained in preparation for their mentoring roles. They learn important skills, such as active listening, encouragement, and the balance between challenge and support, which are necessary in the development of mentoring relationships. In addition, peer mentors are made aware of available support services on campus, such as the counseling center, learning assistance center, career development center, tutoring, and other academic support services. Returning mentors who display strong leadership skills and commitment to the program have the opportunity to be hired as a coordinator. Five coordinators are hired to assist in the management of the mentors and to participate in the planning and implementation of program activities. The mentor coordinators form mentoring relationships among their group of peer mentors to provide additional encouragement and support throughout the fall semester. 
Each year approximately 450 new students register to participate in the fall peer mentoring program. New student participants are matched with upper-level mentors based on major, gender, and other SEEDS program participation. These smaller mentoring groups consist of one mentor to approximately five to ten mentees. These groups are typically enrolled in the same academic coursework and may participate in other SEEDS programs together, such as the Flexus and Virtus.

During the first week of classes, a welcome 'kick-off' event is held as a first opportunity for mentees to meet their peer mentors and mentor coordinators. At least once each month, programwide social and academic events and activities are planned for all program participants. These networking events are designed to facilitate interactions and build community among both participants and mentors. In addition to attending program-wide events with their mentees, mentors maintain consistent contact with their mentees throughout the semester. Many meet with their mentees on a weekly basis. Mentors are required to summarize their contact with mentees each week through completion of an online report. These reports are submitted electronically to coordinators, who, in turn, summarize the peer mentor reports for the program directors. The reports allow for issues to be identified and quickly addressed. If students have any academic, social, or personal issues, the SEEDS staff intervenes to directly address problems at the source.

The mentoring program is designed to benefit mentors, coordinators, and mentees alike (Wallace et al., 2004). Through the development of structured mentoring relationships, participants in the program build self-efficacy and develop leadership and communication skills (Baier et al., 2016). Ultimately, the program seeks to improve upon the student experience, particularly for women and underrepresented minorities, in an effort to better support and retain students in engineering (Wallace et al., 2004).

\section{First Year Summer Experience}

The First Year Summer Experience (FYSE) program is a three-week residential summer orientation program focused on the development and strengthening of math-intensive engineering problem solving skills. All new students offered admission to engineering or students applying to engineering who were admitted to the university but not directly to engineering are eligible to participate. Recruitment and selection of participants is geared toward inclusion of women, racial/ethnic minorities, first-generation college students, and engineering admits with weak mathematics preparation. Approximately 40-60 first-year students participate in the program each summer. The participants are required to live on campus for the duration of the three-week program.

The main goal of the FYSE program is to strengthen engineering-related mathematics skills, with particular focus on pre-calculus and the application of engineering problem solving. This goal contributes to both the academic and self-efficacy development of students as they transition into the academically-demanding environment of engineering (Seymour et al., 1994). The coursework is taught by faculty members and instructors supported by undergraduate teaching assistants. Students have homework assignments, exams, and an engineering group project and final presentation. Upper-level engineering students are hired as tutors to assist students each weeknight in the residence hall. 
In addition to the academic components, the FYSE program seeks to cultivate community and a network of support among each cohort (Tinto, 2003). Team building is strengthened through various activities, such as a group challenge-by-choice course, field trips, research laboratory visits and recreational activities. Furthermore, the FYSE program assists in facilitating students' acclimation to the Clark School. Students participate in a series of seminars featuring engineering faculty from various departments. During one of these seminars, students have the opportunity to have an open dialogue with the engineering Deans. These sessions provide a unique opportunity for students to begin developing a strong network of support, while becoming exposed to various research and extracurricular opportunities offered throughout campus (Soldner et al., 2012; Tinto, 2003). FYSE students continue to receive support from program staff following the completion of the summer program. Like the living and learning students, FYSE participants are provided with mid-semester advising.

\section{Purpose of the Study}

Our study examined whether participation in one or more of the SEEDS programs had a positive impact on the retention of engineering undergraduates within major. This study also examined whether the SEEDS programs were positively impacting the retention of underrepresented groups in engineering (i.e., women and underrepresented racial/ethnic groups) within an engineering major.

To better understand the impact that participation in SEEDS programs had on student retention in engineering compared to engineering undergraduates who did not participate in SEEDS programs (non-SEEDS), the study followed cohorts of SEEDS participants and compared their retention status to non-SEEDS peers. An examination of overall retention of SEEDS participants in comparison to engineering undergraduates who did not participate was conducted. A more refined analysis was performed to determine whether the type of SEEDS program had an impact, specifically if there were differences between four groups: mentoring only, LLC only (i.e., Flexus and Virtus), LLC and mentoring, and non-SEEDS. Finally the impact of SEEDS participation on the retention of underrepresented groups compared to their underrepresented engineering undergraduate peers was examined. Separate analyses were conducted to examine the retention status of women in SEEDS programs versus their non-SEEDS female peers. Similarly, an examination of retention of underrepresented racial/ethnic minorities in SEEDS programs versus their non-SEEDS racial/ethnic peers was performed.

From 2010 to $2015,1,707$ students participated in one or more SEEDS programs. There is variation in the demographic representation by group in comparison to the broader engineering undergraduate population (refer to Table 1). For instance, the percentage of female and male racial/ethnic minority SEEDS participants mirrors the percentage of racial/ethnic minority nonSEEDS students. The percentage of majority female SEEDS participants tends to be slightly higher across cohort years than majority female non-SEEDS students. SEEDS programs capture a percentage of majority male participants with considerable variability by year. 
Table 1. Racial/ethnic demographic breakdown of program participants compared to nonparticipant engineering first-year peers, 2010-2015

\begin{tabular}{lcc}
\hline Demographics & $\begin{array}{c}\text { Total Number of } \\
\text { SEEDS Participants }\end{array}$ & $\begin{array}{c}\text { Total Number of } \\
\text { Non-SEEDS }\end{array}$ \\
\hline Female Minority & 99 & 59 \\
Female Majority & 549 & 308 \\
Male Minority & 133 & 195 \\
Male Majority & 926 & 1337 \\
Total & 1707 & 1899 \\
\hline
\end{tabular}

\section{Methodology}

The sample for the study included cohorts of SEEDS participants and their non-SEEDS peers from fall 2010 - fall 2015. Given the low number of FYSE students who participated in just the FYSE $(n=9)$ these students were removed from the refined analysis by program. Table 2 summarizes the number of participants in each program by cohort.

Table 2. Program participation by cohort year

\begin{tabular}{crrrrrr}
\hline & $\begin{array}{c}\text { Mentoring } \\
\text { Only }\end{array}$ & $\begin{array}{c}\text { SEEDS Program } \\
\text { LLC \& } \\
\text { Year }\end{array}$ & $\begin{array}{c}\text { FLC Only } \\
\text { Mentoring }\end{array}$ & $\begin{array}{c}\text { FY } \\
\text { Only }\end{array}$ & $\begin{array}{c}\text { Non- } \\
\text { SEEDS }\end{array}$ & Total \\
\hline $\mathbf{2 0 1 0}$ & 64 & 5 & 41 & 0 & 39 & 149 \\
$\mathbf{2 0 1 1}$ & 251 & 17 & 60 & 0 & 416 & 744 \\
$\mathbf{2 0 1 2}$ & 118 & 46 & 59 & 8 & 455 & 686 \\
$\mathbf{2 0 1 3}$ & 334 & 30 & 80 & 1 & 261 & 706 \\
$\mathbf{2 0 1 4}$ & 93 & 0 & 97 & 0 & 526 & 716 \\
$\mathbf{2 0 1 5}$ & 293 & 6 & 104 & 0 & 202 & 605 \\
Total & 1153 & 104 & 441 & 9 & 1899 & 3606 \\
\hline
\end{tabular}

${ }^{1}$ The 2010 cohort included only women. Starting in 2011 men were included in the SEEDS programs and the non-SEEDS student counts.

Institutional records were used to garner the status of SEEDS participants and non-SEEDS peers with regard to current major, retention or graduation status, GPA, cumulative credit hours, and duration of living and learning community program participation. Institutional records also provided the demographic data associated with each student including gender and racial/ethnic minority/majority status.

Several comparisons were conducted between SEEDS participants and non-SEEDS peers. A $2 \times 2$ Chi Square analysis was used to determine whether SEEDS participants were retained within engineering at a higher rate than non-SEEDS peers. Following this analysis a $4 \times 2$ Chi Square analysis was conducted to determine whether there were differences in retention between the three types of SEEDS programs and non-SEEDS peers. Given the goals of the SEEDS program, a similar $4 \times 2$ Chi Square analysis was conducted to determine whether women were retained in engineering based on SEEDS program participation. A separate Chi Square analysis was also conducted for minority versus majority students to determine if minority students were retained at higher rates based on program participation. 


\section{Results}

SEEDS Compared to Non-SEEDS. Overall SEEDS participants are retained at a significantly higher rate than non-SEEDS students $\left(p \leq 0.005, X^{2}=7.928\right)$ as shown in Table 3.

Table 3. Retention of SEEDS participants compared to non-SEEDS participants

\begin{tabular}{lccc}
\hline & $\begin{array}{c}\text { Left } \\
\text { Engineering } \\
\%(\mathbf{n})\end{array}$ & $\begin{array}{c}\text { Retained } \\
\text { Engineering } \\
\%(\mathbf{n})\end{array}$ & $\begin{array}{c}\text { Total } \\
\mathbf{n}\end{array}$ \\
\hline SEEDS & $20.2 \%(345)$ & $79.8 \%(1362)$ & 1707 \\
Non-SEEDS & $24.1 \%(458)$ & $75.9 \%(1441)$ & 1899 \\
Total & $22.3 \%(803)$ & $77.7 \%(2803)$ & 3606 \\
\hline
\end{tabular}

The $4 \times 2$ Chi Square revealed that participants who engaged in both the LLC and mentoring programs had the highest retention rate $\left(p \leq 0.002, X^{2}=14.533\right)$. Regardless of program, the SEEDS students were retained within engineering at rates higher than their non-SEEDS peers (refer to Table 4).

Table 4. Retention of SEEDS participants compared to non-SEEDS participants by SEEDS program

\begin{tabular}{lccr}
\hline & $\begin{array}{c}\text { Left } \\
\text { Engineering } \\
\mathbf{\%}(\mathbf{n})\end{array}$ & $\begin{array}{c}\text { Retained } \\
\text { Engineering } \\
\mathbf{\%}(\mathbf{n})\end{array}$ & $\begin{array}{c}\text { Total } \\
\mathbf{n}\end{array}$ \\
\hline LLC and Mentoring & $16.1 \%(71)$ & $83.9 \%(370)$ & 441 \\
LLC Only & $18.3 \%(19)$ & $81.7 \%(85)$ & 104 \\
Mentoring Only & $21.9 \%(252)$ & $78.1 \%(901)$ & 1153 \\
Non-SEEDS & $24.1 \%(458)$ & $75.9 \%(1441)$ & 1899 \\
Total & $22.2 \%(800)$ & $77.8 \%(2797)$ & 3597 \\
\hline
\end{tabular}

Women. Female SEEDS participants are retained at rates similar to their male SEEDS peers $\left(p=0.288, X^{2}=1.125\right.$, refer to Table 5).

Table 5. Retention of women SEEDS participants compared to male SEEDS participants

\begin{tabular}{lccc}
\hline & $\begin{array}{c}\text { Left } \\
\text { Engineering } \\
\%(\mathbf{n})\end{array}$ & $\begin{array}{c}\text { Retained } \\
\text { Engineering } \\
\%(\mathbf{n})\end{array}$ & $\begin{array}{c}\text { Total } \\
\mathbf{n}\end{array}$ \\
\hline Female SEEDS & $18.8 \%(122)$ & $81.2 \%(526)$ & 648 \\
Male SEEDS & $21.0 \%(220)$ & $79.0 \%(830)$ & 1050 \\
Total & $20.1 \%(342)$ & $79.9 \%(1356)$ & 1698 \\
\hline
\end{tabular}

Table 6 summarizes the retention status of women engineering majors only. The 2x2 Chi Square analysis of retention status reveals that women who participate in SEEDS programs are retained significantly higher rates than non-SEEDS women $\left(p \leq 0.05 ; X^{2}=3.789\right)$. 
Table 6. Retention of women SEEDS participants compared to women non-SEEDS participants

\begin{tabular}{lccc}
\hline & $\begin{array}{c}\text { Left } \\
\text { Engineering } \\
\%(\mathbf{m})\end{array}$ & $\begin{array}{c}\text { Retained } \\
\text { Engineering } \\
\%(\mathbf{n})\end{array}$ & $\begin{array}{c}\text { Total } \\
\mathbf{n}\end{array}$ \\
\hline SEEDS & $18.8 \%(122)$ & $81.2 \%(526)$ & 648 \\
Non-SEEDS & $24.0 \%(88)$ & $76.0 \%(279)$ & 367 \\
Total & $20.7 \%(210)$ & $79.3 \%(805)$ & 1015 \\
\hline
\end{tabular}

Examining the results more closely using a $4 \times 2$ Chi Square, women participating in the LLC and mentoring have the highest retention rate $\left(p \leq 0.0001 ; X^{2}=18.329\right.$; as shown in Table 7$)$.

Table 7. Retention of women SEEDS participants compared to women non-SEEDS by program

\begin{tabular}{lccrr}
\hline & $\begin{array}{c}\text { Left } \\
\text { Engineering } \\
\%(\mathbf{n})\end{array}$ & $\begin{array}{c}\text { Retained } \\
\text { Engineering } \\
\%(\mathbf{n})\end{array}$ & $\begin{array}{c}\text { Total } \\
\text { n }\end{array}$ \\
\hline LLC and Mentoring & $11.9 \%$ & $(29)$ & $88.1 \%(214)$ & 243 \\
LLC Only & $13.5 \%$ & $(7)$ & $86.5 \%(45)$ & 52 \\
Mentoring Only & $24.4 \%$ & $(86)$ & $75.6 \%(267)$ & 353 \\
Non-SEEDS & $24.0 \%(88)$ & $76.0 \%(279)$ & 367 \\
Total & $20.7 \%(210)$ & $79.3 \%(805)$ & 1015 \\
\hline
\end{tabular}

Racial/Ethnic Minority and Majority Student Comparison. As shown in Table 8, minority SEEDS participants are retained at similar rates to the majority SEEDS participants $(p=0.767$, $\left.X^{2}=0.87\right)$.

Table 8. Retention of SEEDS minority participants compared to SEEDS majority participants

\begin{tabular}{lccr}
\hline & $\begin{array}{c}\text { Left } \\
\text { Engineering } \\
\%(\mathbf{m})\end{array}$ & $\begin{array}{c}\text { Retained } \\
\text { Engineering } \\
\%(\mathbf{m})\end{array}$ & $\begin{array}{c}\text { Total } \\
\text { n }\end{array}$ \\
\hline Majority SEEDS & $20.0 \%(294)$ & $80.0 \%(1174)$ & 1468 \\
Minority SEEDS & $20.9 \%(48)$ & $79.1 \%(182)$ & 230 \\
Total & $20.1 \%(342)$ & $79.9 \%(1356)$ & 1698 \\
\hline
\end{tabular}

Looking only at minority students, SEEDS participants are retained at significantly higher rates than their non-SEEDS peers ( $p \leq 0.002 ; X^{2}=9.608$; as shown in Table 9).

Table 9. Retention of minority SEEDS participants compared to non-SEEDS minority participants

\begin{tabular}{lccc}
\hline & $\begin{array}{c}\text { Left } \\
\text { Engineering } \\
\mathbf{\%}(\mathbf{n})\end{array}$ & $\begin{array}{c}\text { Retained } \\
\text { Engineering } \\
\mathbf{\%}(\mathbf{n})\end{array}$ & $\begin{array}{c}\text { Total } \\
\mathbf{n}\end{array}$ \\
\hline SEEDS & $20.9 \%(48)$ & $79.1 \%(182)$ & 230 \\
Non-SEEDS & $33.5 \%(85)$ & $66.5 \%(169)$ & 254 \\
Total & $27.5 \%(133)$ & $72.5 \%(351)$ & 484 \\
\hline
\end{tabular}


Across programs, shown in Table 10, minority students that participate in the combination of mentoring and LLC programs have the highest rate of retention at $91.3 \%$ and are retained at substantially higher rates than non-SEEDS peers $\left(p \leq 0.003 ; X^{2}=13.947\right)^{l}$.

Table 10. Retention of minority SEEDS participants compared to minority non-SEEDS participants ${ }^{l}$

\begin{tabular}{lcccc} 
& $\begin{array}{c}\text { Left } \\
\text { Engineering } \\
\%(\mathbf{m})\end{array}$ & $\begin{array}{c}\text { Retained } \\
\text { Engineering } \\
\%(\mathbf{n})\end{array}$ & $\begin{array}{c}\text { Total } \\
\text { n }\end{array}$ \\
\hline LLC and Mentoring & $8.7 \%$ & $(4)$ & $91.3 \%(42)$ & 46 \\
LLC Only & $26.7 \%$ & $(4)$ & $73.3 \%(11)$ & 15 \\
Mentoring Only & $23.7 \%$ & $(86)$ & $76.3 \%(129)$ & 169 \\
Non-SEEDS & $33.5 \%(85)$ & $66.5 \%(169)$ & 254 \\
Total & $27.5 \%(133)$ & $72.5 \%(351)$ & 484 \\
\hline
\end{tabular}

${ }^{1}$ Given the low cell counts in the $4 \times 2$ Chi Square analysis, statistical comparisons of frequency of retention cannot be performed.

\section{Discussion}

The findings of this study indicate that participation in the SEEDS programs positively impacts retention to engineering in comparison to nonparticipants. Furthermore, these finding suggest that the SEEDS programs help to build an inclusive community among participants, contributing to a greater likelihood of retention. It appears that the combination of academic support and social integration allow for a sense of community to develop through a shared experience. Additionally, the career development that is provided may help first year students connect their experience to long term goals that they want to achieve.

Positive outcomes related to retention are seen across groups, including women and racial/ethnic minority students when compared to non-SEEDS peers. Higher levels of retention may be due to the fact that SEEDS programs provide an immediate link to other underrepresented populations in the Clark School of Engineering through LLCs and regular networking events.

Regardless of the type of SEEDS program in which they participated (i.e., LLC, mentoring, or the combination of LLC and mentoring), engineering undergraduates were more likely to be retained within engineering than peers who did not participate in SEEDS programming. Moreover, based on the study's findings it appears that participation in the LLC programs (i.e., Flexus and Virtus) in combination with the mentoring program may have the most positive implications for student retention. Reflected in the results, as a whole SEEDS students who participated in the combination of living and learning communities and mentoring were retained at $83.9 \%$. When examined by sub-group, $88.1 \%$ of the women, and $91.3 \%$ of the minority students were retained within engineering if they participated in a LLC and mentoring. The combination of a living and learning community coupled with purposeful mentoring from more advanced peers may provide program participants with the encouragement and resources they need from others. Likewise, receiving advice and guidance from peers who may have had similar struggles during their first year may help facilitate positive identity development among participants in regards to what it means to succeed in engineering. 


\section{Limitations}

The quantitative study was limited to understanding whether participation in SEEDS programs make a difference in the retention status of engineering undergraduates in comparison to undergraduates who do not participate. In future work this will be expanded upon to more clearly understand which programmatic aspects are influencing the retention status through in-depth interviews with participants and non-SEEDS students. Future studies will also look to control for additional factors that may influence student retention such as motivation or prior academic preparation. Additionally, while this study provided a breakdown by program to understand if there were differences in the manner in which participation impacted retention, it was not possible to gain insight into how the FYSE program may influence retention. Future research could specifically exam the impact of the FYSE program and how it may make a unique contribution to the continued enrollment and academic progress of engineering students.

\section{Implications}

Despite these limitations, these findings can be useful in the future development and implementation of undergraduate engineering retention programs. Program administrators may consider the SEEDS program structure as a model for program design, implementation, and in the assessment of retention. While many institutions offer LLCs and mentoring programs, these programs may not necessarily be aligned in the effective ways in which the SEEDS programs have been implemented. Program administrators may consider embedding a mentoring component within the LLC program design to maximize the benefits of such retention programming.

The SEEDS method of program evaluation has been regarded as a best practice within university. In addition to program implementation, program administrators and practitioners of other living and learning communities may consider adopting the evaluations plan of the SEEDS programs to better assess the efficacy and implications of program development and implementation.

Through the intentional support structure of SEEDS programs, students are exposed to mentors and role models, guided to succeed in academically challenging environments, and encouraged within communities of social and professional development and support. In addition, participants of the living and learning communities, particularly in Flexus, have developed long-term friendships through the program, which contribute to continued networks of encouragement and support (Samuelson et al., 2014). While developed and implemented to better retain students in the Clark School, the benefits of the SEEDS programs extend beyond degree completion, through the development of successful leaders and professionals in the field of engineering.

\section{References}

Baier, S. T., Markman, B. S., \& Pernice-Duca, F. M. (2016). Intent to persist in college freshmen: The role of self-efficacy and mentorship. Journal of College Student Development, 57(5), 614-619. 
Lee, W.C., Seimetz, C.N, and Amelink, C.T. (2014). Examining the transition to engineering: A multi-case study of six diversity summer bridge program participants. Proceedings of the 2014 American Society for Engineering Education Annual Conference and Exposition.

National Academies: Committee on Underrepresented Groups and the Expansion of the Science and Engineering Workforce Pipeline; Committee on Science, Engineering and Public Policy and Global Affairs; and National Academy of Sciences, National Academy of Engineering, and Institute of Medicine. (2014). Expanding underrepresented minority participation: America's science and technology talent at the crossroads, National Academies Press.

Samuelson, C., Litzler, E., Staples, C., \& Smith, P. (2014). Living, learning, and staying: The impact of a women in engineering living and learning community. Proceedings of the 2014 American Society for Engineering Education Annual Conference and Exposition.

Seymour, E., \& Hewitt, N. (1994). Talking about leaving: Factors contributing to high attrition rates among science, math, and engineering undergraduate engineering majors. Final report to the Alfred P. Sloan Foundation on Ethnographic Inquiry at Seven Institutions. Boulder, CO.

Smith, P., Fourney, W., \& Pertmer, G. (2009). Successful engineering education and development support (SEEDS) program, Proposal to the Science, Technology, Engineering, and Mathematics Talent Expansion Program, National Science Foundation.

Soldner, M., Rowan-Kenyon, H., Inkelas, K. K., Garvey, J., \& Robbins, C. (2012). Supporting Students' intentions to persist in STEM disciplines: The role of living-learning programs among other social-cognitive factors. The Journal of Higher Education, 83(3), 311-336.

Tinto, V. (2003). Learning better together: The impact of learning communities on student success. Higher Education Monograph Series, 1(8).

Wallace, J. E., \& Haines, V. A. (2004). The benefits of mentoring for engineering students. Journal of Women and Minorities in Science and Engineering, 10(4).

Yoder, B. (2012). Going the distance in engineering education: Best practices and strategies for retaining engineering, engineering technology, and computing students. Proceedings of the 2012 American Society for Engineering Education Annual Conference and Exposition. 